\title{
Improved Knowledge, Attitudes, and Practices of Balanced Nutrition after Educational Intervention Based on the Self-determination Theory: An Intervention Study in Senior School Teachers in Makassar City
}

\author{
Nurhaedar Jafar ${ }^{1}$, Nurzakiah Hasan², Veni Hadju', Ridwan M. Thaha ${ }^{3}$, Andi I. Arundhana ${ }^{1 *}$ \\ ${ }^{1}$ Department of Nutrition, School of Public Health, Hasanuddin University, Makassar, South Sulawesi, Indonesia; ${ }^{2}$ Department \\ of Nursing, Health College Baramuli, Pinrang, South Sulawesi, Indonesia; ${ }^{3}$ Department of Health Promotion, School of Public \\ Health, Hasanuddin University, Makassar, South Sulawesi, Indonesia
}

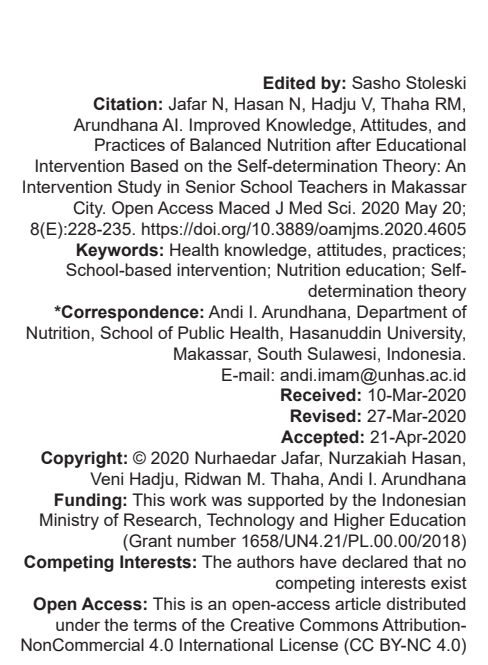

Abstract

BACKGROUND: Studies linking the association of nutrition knowledge, attitudes, and practices (KAP) with healthy behavior have been well established. However, the method to effectively deliver nutrition education to a particular population, especially middle-income population, was less studied.

AIM: This study aimed to examine the effects of school-based nutrition using the self-determination theory (SDT) on nutrition KAP of the senior secondary schoolteacher with metabolic syndrome risk.

METHODS: This study was a non-randomized pre-post intervention study conducted in eight senior secondary schools in Makassar City. The intervention group received a balanced nutrition package either delivered through modules, balance sheet (calendar), or physical activity poster for 4 months. The control group received a pamphlet that has been developed by the Ministry of Health of the Republic of Indonesia.

RESULTS: A total of 123 respondents ( 63 respondents) intervention and (60 respondent) control group completed post-test and were included in the analysis. There were increase knowledge, attitude, and practice in both groups but increasing in the intervention group was a significant relationship compared to the control group (knowledge $\mathrm{p}<0.001$ and practice $=0.007) . \mathrm{s}$

CONCLUSIONS: Delivering nutrition education using SDT concept can potentially improve the knowledge and practices of the teachers about balanced nutrition. The government may adopt the SDT approach when designing the nutrition education program with specific targets.

\section{Introduction}

In 2016, the WHO reported that noncommunicable diseases (NCDs) are the leading cause of illness and premature death in the world. These diseases are responsible for 40.5 million or $71 \%$ of global mortality. The Lancet Global Health indicated that NCDs are associated with socioeconomic status [1]. Thus, it is reasonable, based on the fact that NCDs dominantly occurred in low-middle income countries, including Indonesia. It is reported Indonesia had the secondhighest deaths caused by NCDs among Southeast Asian Countries with estimation about 800 NCDs patients per 100,000 Indonesian population [2]. This problem may trigger the risk of mortality and adults at reproductive age are vulnerable the most [3]. The primary NCDs, such as cardiovascular, diabetes mellitus [4], stroke, and cancer, are preceded by various metabolic disorders, known as metabolic syndrome (MetS) [5].
MetS represents metabolic disturbances affecting the physiological and health outcome of human [6]. A person is defined with MetS when three or more of the following indicators present, including high blood sugar levels, abdominal obesity, high blood pressure, high blood triglyceride levels, and low levels of high dentistry lipoprotein (HDL) cholesterol [7], [8]. Although some evidence relates these symptoms to genetic, it could not be denied that most of them are driven by unhealthy lifestyles, such as poor diet and physical inactivity. A recent study indicates that a person who has the highest category of healthy lifestyle adherence enjoyed a significant reduction of MetS risk than those in the lowest adherence category [9].

The latest Indonesian Family Life Survey in 2013 reported that the prevalence of MetS was 21.66\% [10]. Herningtyas et al. demonstrated that South Sulawesi Province was one of the highest contributors of MetS in Indonesia with $22.83 \%$, and the MetS prevalence among 
the Makassar ethnic population was $28.28 \%$ [10]. A high prevalence of MetS is strongly caused by imbalance food intakes. As Hardinsyah reported, the fat and salt intakes of Indonesian people were higher than the WHO recommendation $(64.7 \mathrm{~g} / \mathrm{cap} / \mathrm{d}$ and $5.7 \mathrm{~g} / \mathrm{cap} / \mathrm{d}$, respectively) [11]. In line with the previous finding, a study conducted in Jakarta indicated that high blood pressure was the most cause of MetS in men, while central obesity in women [12]. Most findings in the literature contended that unhealthy lifestyles are associated with the level of knowledge, attitudes, and practices (KAP).

A poor KAP leads individual to consume unhealthy foods which are based on their appetite, and this situation may promote MetS. A study in Sri Lanka population demonstrated the positive association between KAP scores and the risk of cardiovascular diseases (CVD) [13]. Giving nutrition knowledge, attitude, and practice is essential and will result multiple benefits in their lifestyle behavior and subsequently their health [14], [15]. However, there is no current "best" approach to deliver nutrition knowledge, especially for those living in the urban areas which may have high education and other indicators of socioeconomic status.

In our preliminary study, it was shown that balanced nutrition knowledge and practice were associated with the incidence of MetS. Respondents who had a high education level were followed by poor nutrition practices, although they had good knowledge [16]. Some studies used the self-determination theory (SDT) to deliver counseling showed a positive effect on the results [17], [18], [19]. Patrick and Williams defined SDT as "a general theory of human motivation that emphasizes the extent to which behaviors are relatively autonomous (i.e., the extent to which behaviors originate from the self) versus relatively controlled (i.e. the extent to which behaviors are pressured or coerced by intrapsychic or interpersonal forces)" [20]. Principally, there are three domains in basic psychological needs involved in this theory, including autonomy, competence, and relatedness. Therefore, this study was aimed to examine the effects of school-based nutrition education using the SDT approach in the senior secondary high school teacher in Makassar on the change of nutrition knowledge, attitudes, and practices.

\section{Methodology}

\section{Recruitment and data collection}

A pre-post interventional study was carried out among civil servant teachers in Makassar City. There are 2886 numbers of teachers who still active in teaching, but we purposively selected participants from three sub-district with the highest number of teachers, namely, Biringkanayya, Tamalanrea, and Manggala subdistrict. In these areas, there are 12 schools, but four schools were excluded due to the number of teachers who were willing to participate was small $(<6)$. From included schools $(n=8)$, a total of 154 teachers meeting the following criteria were invited to participate (Figure 1): Status as civil servant teachers and willing to participate in 3 years of research. Midpoint analysis has been done to only 129 participants and has been published [16]. However, at the end of the study, only 123 teachers could be further analyzed as 31 were dropped out with some reasons, such as sick, declined to participate, pregnant, and traveled overseas. Those who were pregnant and diagnosed with diabetes mellitus and CVD by health professionals were excluded from the study.

\section{Group allocation and intervention}

The group allocation was purposively done by giving autonomy to the schools to decide in which treatment they would like to involve. The way to decide which schools are intervention and control groups was through discussion with the authority of the school (i.e., vice headmaster). All teachers in the schools which chose to participate as intervention group was required to actively participate as they would have four monthly interactive seminars meetings using SDT concept. At the first meeting, all respondents will give the opportunity to assess the results of the examination related to five parameters in MetS. It was expected that all respondents can determine the current health condition and the magnitude of the problems they had since the first meeting. The next three meetings, the information about balanced nutrition guidelines was provided and motivation for respondents to follow the guidelines was emphasized. In the intervention group, there are three means of intervention as follows:

\section{Module}

We used the modules of balanced nutrition adopted from the Indonesian Ministry of Health [21]. The module distributed in a monthly basis consists of four topics, namely, (1) understanding health problems and consumption of fruit vegetables; (2) physical activity and maintain ideal body weight; (3) intake limitation for sweet, salty, and fatty foods as well as read labels behavior on food packaging; and (4) encourage behavior for having breakfast and drink adequate water. The purpose of this module was to give an intensive exposure of balanced nutrition information to the teachers.

\section{Calendar}

The calendar contains information on each sheet of the month about practical healthy behaviors 


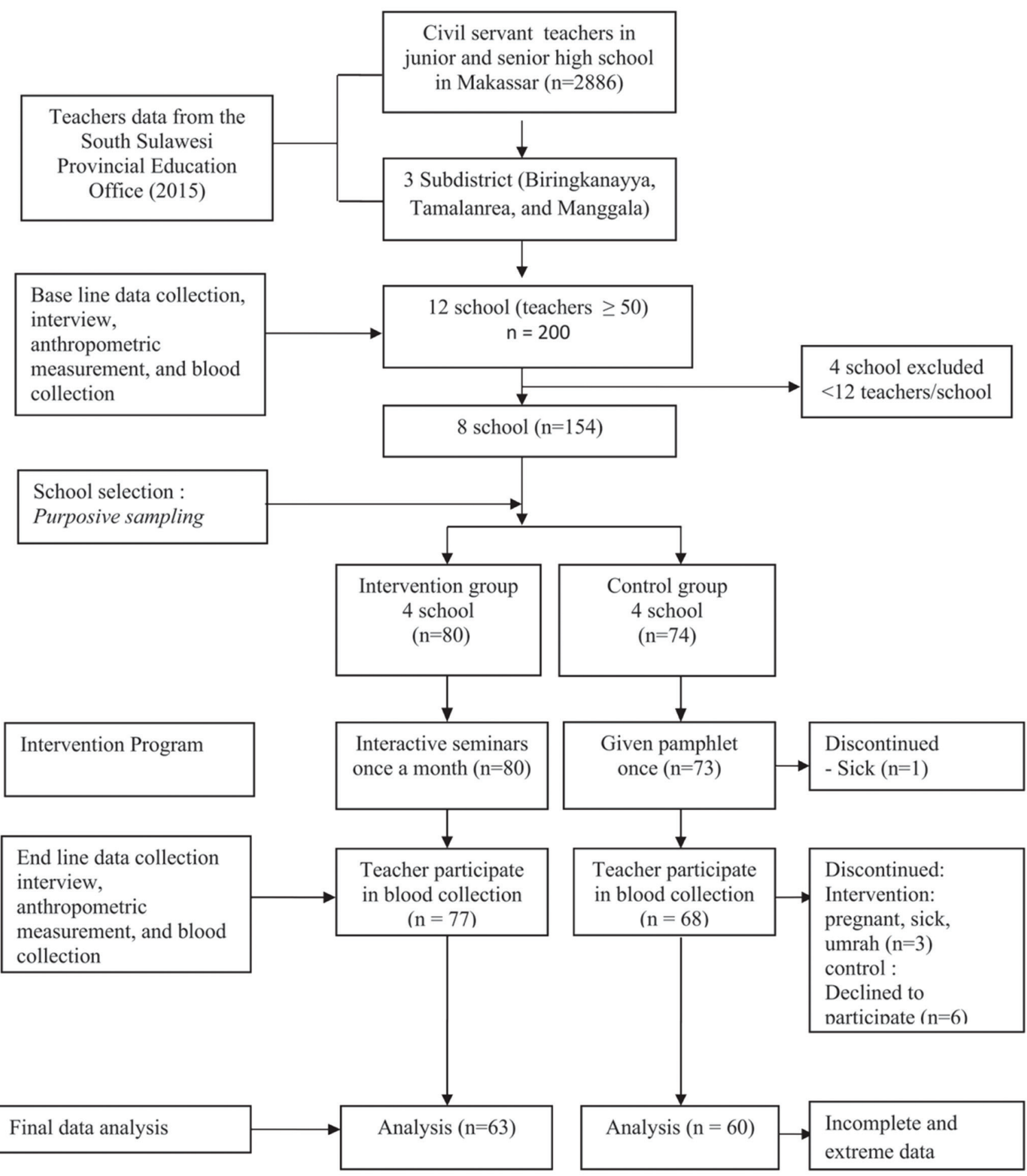

Figure 1: School and respondent recruitment

that could be easily done by the teachers. We develop the intervention in the form of a table calendar with the aim that the calendar can be put on the teacher's desk, and thus will always be seen by them.

\section{Poster}

The poster emphasizes the information on physical activities. The poster was placed in the strategic places at schools, such as notification or wall-magazine boards. Hence, teachers were easily exposed.

On the other hand, teachers from four control group schools were exposed with balanced nutrition information through pamphlet which was developed by the Indonesian Ministry of Health [21]. The meeting with the control group only has been conducted once during intervention. In addition to that, a brief presentation about MetS and the ten messages of balanced nutrition were also delivered (Table 1). 
Table 1: The 10 basic messages in balanced nutrition guideline

\begin{tabular}{ll}
\hline Message number & Message text \\
\hline 1 & Eat variety of foods \\
2 & Eat plenty of vegetables and fruits \\
3 & Eat high-protein foods (animal or vegetable source) \\
4 & Eat a variety of staple foods \\
5 & Limit consumption of sweet, salty and fatty foods \\
6 & Eat breakfast every day \\
7 & Drink enough safe water \\
8 & Read food labels \\
9 & Wash your hands with soap and running water \\
10 & Perform adequate physical activity and maintain a normal weight \\
\hline
\end{tabular}

\section{Data collection}

MetS defined using harmonizing the MetS, the multiple joint agreement world organization international of diabetes federation task force on epidemiology and prevention; national heart, lung, and blood institute; American heart association; world heart federation; international atherosclerosis society; and international association for the study of obesity [8]. Respondents classified as having MetS if they have three or more of five following parameters: abdominal circumference (>90 cm for men and >80 cm for women); HDL levels ( $<40 \mathrm{mg} / \mathrm{dl}$ for male and $<50 \mathrm{mg} / \mathrm{dl}$ for female); blood pressure (>130/85 mmHg); triglycerides (>150 mg/dl); and fasting blood glucose (levels $>100 \mathrm{mg} / \mathrm{dl}$ ). Based on these indicators, we reported in the previous study the prevalence of Mets among the study population which reached $39.5 \%$, and this number was lower in men than in women (31.4\% vs. 68.6\%) [16].

Anthropometric measurements were carried out before and after intervention by trained staff. Body height measured using stadiometer required participants remove footwear and hats. Body weight was measured using Camry digital scales and carried out after the respondent removes all the items from his pocket and take off his/her shoes. Abdominal circumference was measured using a measure tape.

\section{Questionnaire}

The questionnaire used in this study was developed and was validated with two validation processes (Table 2). This questionnaire was used to assess KAP based on balanced nutrition guideline [21]. After the first validation process, few questions indicating inconsistency were reviewed and modified. The second validation process was then conducted and resulted in reliability (Cronbach's alpha) value more than 0.7 for all variables indicating that the questions are acceptable and reliable to be used.

Table 2: Result of the questionnaire validation process

\begin{tabular}{|c|c|c|c|c|c|}
\hline No & $\begin{array}{l}\text { Variables } \\
\text { proxy }\end{array}$ & $\begin{array}{l}\text { Inter-item } \\
\text { correlation } 1^{\text {st }} \\
\text { validation }\end{array}$ & $\begin{array}{l}\text { Reliability } \\
\text { (Cronbach's alpha) } \\
1^{\text {st }} \text { validation }\end{array}$ & $\begin{array}{l}\text { Inter-item } \\
\text { correlation } \\
2^{\text {nd }} \text { validation }\end{array}$ & $\begin{array}{l}\text { Reliability } \\
\text { (Cronbach's alpha) } \\
2^{\text {nd }} \text { validation }\end{array}$ \\
\hline 1 & Knowledge & 0.162 & 0.684 & 0.255 & 0.790 \\
\hline 2 & Attitude & 0.094 & 0.621 & 0.203 & 0.737 \\
\hline 3 & Practice & 0.036 & 0.474 & 0.204 & 0.769 \\
\hline 4 & $\begin{array}{l}\text { Autonomic } \\
\text { support }\end{array}$ & 0.079 & 0.619 & 0.320 & 0.756 \\
\hline
\end{tabular}

\section{Processing and analyzing the data}

To ensure the quality of the data, checking the consistency and completeness of the questionnaire and conducted double entry to SPSS before analysis has been done. Data analysis was a Chi-square test for dichotomous data and t-test, as well as Wilcoxon signed-rank test for continuous data. The outcome variable compared to pre- and post-intervention.

\section{Results}

The baseline characteristic of participants is shown in Table 3 . There is no significant difference between intervention and control groups for sex, age, marital status, income, and education level.

Table 4 presents the effect on nutrition education package in both groups. There was a significant improved in knowledge and practice scores of the intervention group $(1.0 \pm 2.0 ; p<0.001$ and 2.5 $\pm 6.8 ; p<0.007$, respectively), while there were no changes in the control group.

Table 3: Baseline characteristic of intervention and control group

\begin{tabular}{|c|c|c|c|}
\hline Variable & $\begin{array}{l}\text { Intervention group }(\mathrm{n}=63) \\
\mathrm{n}(\%)\end{array}$ & $\begin{array}{l}\text { Control group }(\mathrm{n}=60) \\
\mathrm{n}(\%)\end{array}$ & $p$ value \\
\hline \multicolumn{4}{|c|}{ (1) } \\
\hline Male & $13(20.6)$ & $13(21.7)$ & \multirow[t]{2}{*}{1.000} \\
\hline Female & 50 (79.4) & 47 (78.3) & \\
\hline \multicolumn{4}{|l|}{ Age group } \\
\hline$<40$ years & $6(9.5)$ & $8(13.3)$ & \multirow[t]{2}{*}{0.703} \\
\hline$\geq 40$ years & $57(90.5)$ & $52(86.7)$ & \\
\hline \multicolumn{4}{|l|}{ Marital status } \\
\hline Unmarried/divorce & $7(11.1)$ & $3(5.0)$ & \multirow[t]{2}{*}{0.324} \\
\hline Married & $56(88.9)$ & $57(95.0)$ & \\
\hline \multicolumn{4}{|l|}{ Income } \\
\hline $\begin{array}{l}\text { Lower } \\
(\leq 4,300,000)\end{array}$ & $31(46.3)$ & $36(53.7)$ & \multirow[t]{2}{*}{0.308} \\
\hline $\begin{array}{l}\text { Higher } \\
(>4,300,000)\end{array}$ & $32(57.1)$ & 24 (42.9) & \\
\hline \multicolumn{4}{|l|}{ Education } \\
\hline $\begin{array}{l}\text { Lower (Senior } \\
\text { secondary school } \\
\text { and bachelor's } \\
\text { degree) }\end{array}$ & $52(82.5)$ & $43(71.7)$ & \multirow[t]{2}{*}{0.194} \\
\hline $\begin{array}{l}\text { Higher (Master and } \\
\text { doctoral degree) }\end{array}$ & $11(17.5)$ & $17(28.3)$ & \\
\hline
\end{tabular}

Figures 2-7 present the changes between pre- and post-intervention for each message in Indonesian Balanced Nutrition Guideline. Figures 2, 4, and 6 illustrate the effect of the intervention on KAP in the intervention group, while Figures 3, 5, and 7 in the control group.

Table 4: Effect of nutrition education in knowledge, attitude, and practice change between intervention and control groups

\begin{tabular}{|c|c|c|c|c|c|}
\hline Variable & Pre-test & Post-test & Diff. & $95 \% \mathrm{Cl}$ & $p$ value \\
\hline \multicolumn{6}{|l|}{ Knowledge } \\
\hline Intervention & $18.38 \pm 2.03$ & $19.35 \pm 1.97$ & $0.97 \pm 2.00$ & $-1.47,-0.47$ & $<0.001^{\mathrm{a}}$ \\
\hline Control & $18.43 \pm 2.19$ & $18.93 \pm 2.06$ & $0.50 \pm 2.14$ & $-1.05,0.05$ & $0.076^{\mathrm{b}}$ \\
\hline \multicolumn{6}{|l|}{ Attitude } \\
\hline Intervention & $39.76 \pm 3.59$ & $40.06 \pm 2.85$ & $0.30 \pm 3.63^{c}$ & $-1.21,0.61$ & $0.512^{b}$ \\
\hline Control & $40.70 \pm 4.39$ & $42.08 \pm 4.09$ & $1.38 \pm 6.27$ & $-3.00,0.24$ & $0.093^{b}$ \\
\hline \multicolumn{6}{|l|}{ Practice } \\
\hline Intervention & $56.98 \pm 7.60$ & $59.40 \pm 6.20$ & $2.41 \pm 6.81$ & $-4.13,-0.70$ & $0.007^{\mathrm{b}}$ \\
\hline Control & $55.97 \pm 6.97$ & $57.82 \pm 6.34$ & $1.85 \pm 7.56$ & $-3.80,0.10$ & $0.063^{b}$ \\
\hline
\end{tabular}




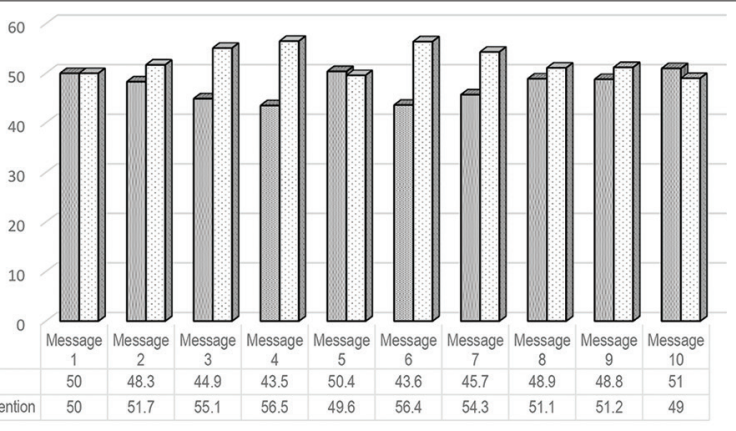

Figure 2: The percentage of teachers in the intervention group answered correctly for the knowledge of the 10 messages in balanced nutrition guidelines

\section{Discussion}

This study examined an emerging theory in motivation, called the SDT, which was embedded in a nutrition education package. The result of the recent study indicated that the education delivered through the SDT-based package to intervention group positively affects the knowledge and practice regarding balanced nutrition, though no effect on attitude. The concept of SDT emphasizes the enhancement of the participant's understanding and motivation and thus, they will have the psychological energy to reach a particular goal in the end [20]. A study has reported that a nutritional

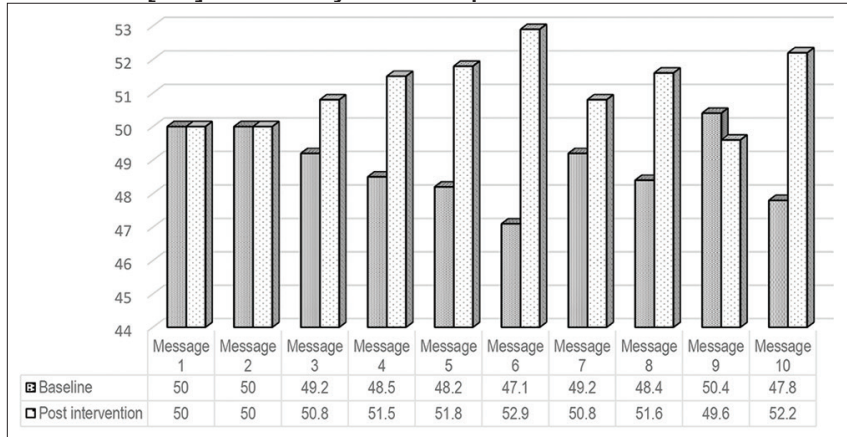

Figure 3: The percentage of teachers in the control group answered correctly for the knowledge of the 10 messages in balanced nutrition guidelines

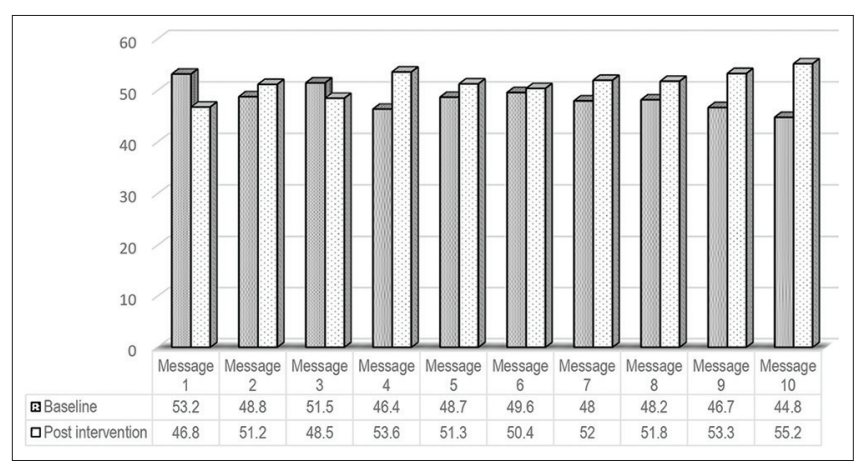

Figure 4: The percentage of teachers in the intervention group answered correctly for the attitude of the 10 messages in balanced nutrition guidelines

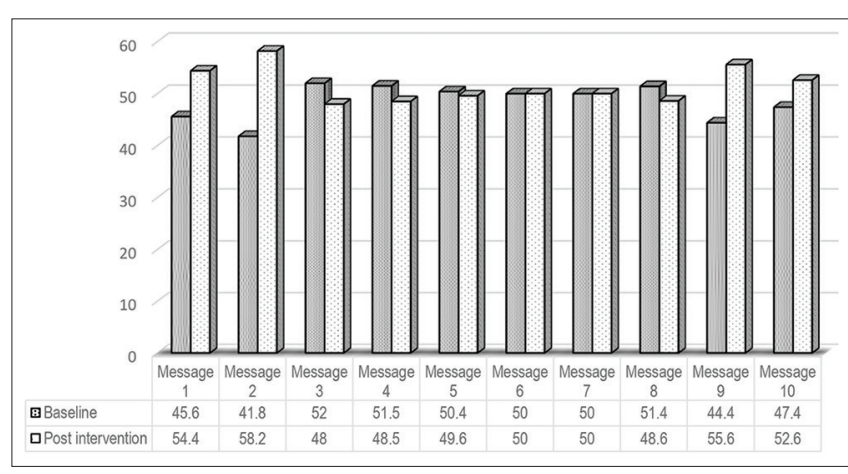

Figure 5: The percentage of teachers in the control group answered correctly for the attitude of the 10 messages in balanced nutrition guidelines

intervention program based on the SDT improved eating motivation and positively associated with the increase of adherence of the Mediterranean diet in response to the intervention [22]. Leblanc et al. (2016) suggested that the SDT may encourage people to have a satisfaction of autonomy, competence, and relatedness leading to promote self-determined motivation. Therefore, delivering nutrition education using the concept of SDT will increase the change to improve KAP through increasing an individual's determined motivation.

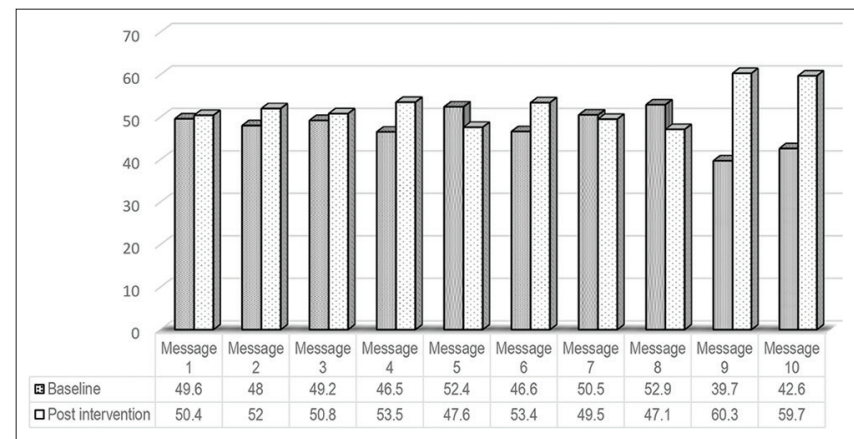

Figure 6: The percentage of teachers in the intervention group answered correctly for the practice of the 10 messages in balanced nutrition guidelines

Education itself has been confirmed can improve behavior-related diseases by mediating the participant's knowledge [23], [24]. A study in Turkey strengthened the evidence that interventions through education can improve knowledge, and thus affecting

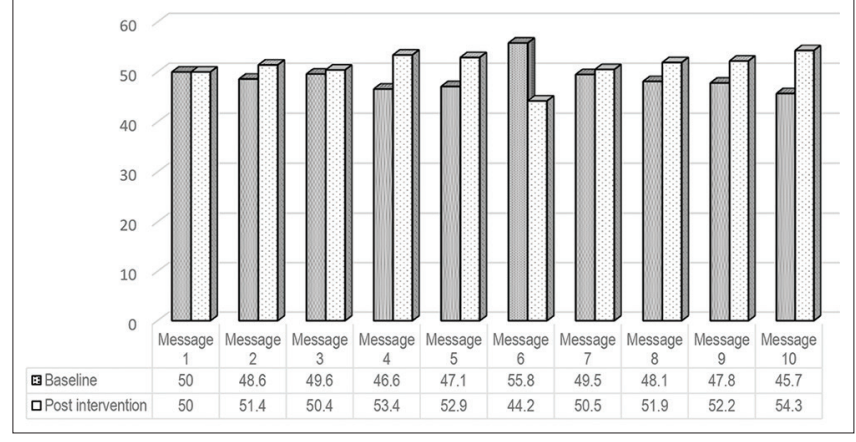

Figure 7: The percentage of teachers in the control group answered correctly for the practice of the 10 messages in balanced nutrition guidelines

someone's behavior [25]. In this study, KAP refers to the 10 principal messages in Indonesian dietary 
guidelines (Table 1). The percentage of teachers in the intervention and control groups who answered correctly for the KAP regarding the 10 messages in balanced nutrition guidelines was shown in Figures 2-7.

The results of the study did not show a significant change in attitude for both groups. It may be due to the fact that all intervention packages included the one given to the control group, do not emphasize the aspect of attitude. In addition, the baseline result showed that the majority of teachers in both groups already have a good attitude, and therefore, it can be difficult to change. It is only reluctant attitudes that can rapidly be changed. A better understanding of particular information underlies the change of attitudes to be more positive, thus educating people is important. If people have resisting attitudes toward health promotion, they are likely to have unhealthy lifestyles compared to others [26]. Conversely, the more people have moderate knowledge and good attitudes, the more likely good practices [27]. In our opinion, good attitudes can be significant in improving a healthy lifestyle when it is supported with adequate knowledge.

The main goal of educating people with health and nutrition information is the modification of their behavior to be better. This study shows that the practice score increased in both groups, though only in the intervention group was significant. It is probably due to the means of education method given to the intervention group were more effective to motivate teachers. Modules, calendars, and posters compiled balanced nutrition practices motivating teachers to do healthy practices. A study reports that education tolls can improve behavior, increasing physical activity, and consumption of vegetables as well as fruits in Australian adults [17]. Intervention given to teachers may promote "internalization" of the materials (balanced nutrition), thus a person may do the activities related to that information provided. Internalization of balanced nutrition information may be partly due to the frequency of exposure to the material which is higher than those received by the control group. Moreover, the level of education may also affect behavior mediating by knowledge. A study indicated knowledge declining with lower education [28]. Thus, increased practice in the control group may be partially affected by their education. In addition, parents' roles, gender, and lack of control over are the other factors underlying unhealthy behavior [28], [29], [30].

Despite the fact that the application of the SDT concept has not improved attitudes, this concept is still applicable to fostering self-determined motivation by improving knowledge of balanced nutrition. As a reaction to this knowledge, people are encouraged to implement balanced nutrition practices. Therefore, it is possible to implement the SDT concept during the implementation of nutrition programs in Indonesia. For example, the compliance of pregnant women to the consumption of iron supplements can be significantly increased by increasing their confidence and motivation. However, further study needs to prove the implementation stage of the SDT concept in the realsetting nutrition program, especially in the population with low-education level.

There were some limitations acknowledged in this study. First, the distribution of this study did not use random allocation. However, the nature of the study made a randomized controlled trial done as it is a school authorization. Second, gender domination (female) may also affect the result of the study. However, the composition of female participants between intervention and control group may reduce the result biases caused by gender.

\section{Conclusions}

In summary, nutrition education using the SDT concept may improve knowledge, emphasizing motivation and thus corroborating practices of balanced nutrition. Although attitude did not significantly change in both groups, it still probably has a contribution to practices. It is suggested to the government that the media of nutrition education for improving a healthy lifestyle may adopt the SDT, especially when targeting a specific population.

\section{Acknowledgments}

The authors thank to all study participants for their time spent during the study. This study was received ethics approval from the Ethics Committee of School of Public Health, Hasanuddin University (protocol ref no: UH17080550). The protocol of the study was registered to Australian New Zealand Clinical Trials Registry (ACTRN 12618000863235, Registered 22 May 2018).

\section{Competing Interest}

The authors declare no conflicts of interest. The funder institution had role in the design of the study; in the collection, analyses or interpretation of data; in the writing of the manuscript, or in the decision to publish the results. 


\section{References}

1. Allen L, Williams J, Townsend N, Mikkelsen B, Roberts $\mathrm{N}$, Foster $\mathrm{C}$, et al. Socioeconomic status and non-communicable disease behavioural risk factors in low-income and lowermiddle-income countries: A systematic review. Lancet Glob Health. 2017;5(3):e277-89. https://doi.org/10.1016/ s2214-109x(17)30058-x PMid:28193397

2. World Health Organization. Noncommunicable Diseases Progress Monitor. Geneva: World Health Organization; 2017.

3. Guariguata L, Whiting DR, Hambleton I, Beagley J, Linnenkamp U, Shaw JE. Global estimates of diabetes prevalence for 2013 and projections for 2035. Diabetes Res Clin Pract. 2014;103(2):137-49. https://doi.org/10.1016/j. diabres.2013.11.002

PMid:24630390

4. $\mathrm{Xu} \mathrm{Y}$, Wang L, He J, Bi Y, Li M, Wang T, et al. Prevalence and control of diabetes in Chinese adults. JAMA. 2013;310(9):948-58. PMid:24002281

5. Kaur J. A comprehensive review on metabolic syndrome. Cardiol Res Pract. 2014;2014:943162.

PMid:24711954

6. Eckel RH, Grundy SM, Zimmet PZ. The metabolic syndrome. Lancet. 2005;365(9468):1415-28. https://doi.org/10.1016/ s0140-6736(05)66378-7

\section{PMid:15836891}

7. Alberti KG, Eckel RH, Grundy SM, Zimmet PZ, Cleeman JI, Donato KA, et al. Harmonizing the metabolic syndrome: A joint interim statement of the international diabetes federation task force on epidemiology and prevention; national heart, lung, and blood institute; American heart association; world heart federation; international atherosclerosis society; and international association for the study of obesity. Circulation. 2009;120(16):1640-5. https://doi.org/10.1161/ circulationaha.109.192644

\section{PMid:19805654}

8. World Health Organization. Diagnosis and Classification of Diabetes Mellitus and its Complications Part 1: Diagnosis and Classification of Diabetes Mellitus. Vol. 15. Geneva: World Health Organization; 1999.

9. Garralda-Del-Villar M, Carlos-Chillerón S, Diaz-Gutierrez J, Ruiz-Canela M, Gea A, Martínez-González MA, et al. Healthy lifestyle and incidence of metabolic syndrome in the SUN cohort. Nutrients. 2019;11(1):1-15. https://doi.org/10.3390/nu11010065 PMid:30598006

10. Herningtyas $\mathrm{EH}, \mathrm{Ng} \mathrm{TS}$. Prevalence and distribution of metabolic syndrome and its components among provinces and ethnic groups in Indonesia. BMC Public Health. 2019;19(1):112. https://doi.org/10.1186/s12889-019-6711-7 PMid:30943932

11. Hardinsyah Analisis konsumsi lemak, gula, dan garam penduduk Indonesia. Gizi Indones. 2011;34:92-100. https://doi. org/10.36457/gizindo.v34i2.105

12. Soewondo P, Purnamasari D, Oemardi $M$, Waspadji $S$, Soegondo S. Prevalence of metabolic syndrome using NCEP/ ATP III criteria in Jakarta, Indonesia: The Jakarta primary noncommunicable disease risk factors surveillance 2006. Acta Med Med Indones. 2010;42(4):199-203.

PMid:21063040

13. Amarasekara $P$, De Silva A, Swarnamali $H$, Senarath UP, Katulanda P. Knowledge, attitudes, and practices on lifestyle and cardiovascular risk factors among metabolic syndrome patients in an urban tertiary care institute in Sri Lanka.
Asia Pac J Public Health. 2016;28(1):32S-40S. https://doi. org/10.1177/1010539515612123

PMid:26512029

14. Spronk I, Kullen C, Burdon C, O'Connor H. Relationship between nutrition knowledgeand dietary intake. BrJNutr. 2014;111(10):171326. https://doi.org/10.1017/s0007114514000087

PMid:24621991

15. Popkin BM. Global nutrition dynamics: The world is shifting rapidly toward a diet linked with noncommunicable diseases. Am J Clin Nutr. 2006;84(2):289-98. https://doi.org/10.1093/ ajcn/84.2.289

PMid: 16895874

16. Hasan NM, Hadju V, Jafar N, Thaha RM. Prevalence of metabolic syndrome (MetS) and determinants among obese teachers in makassar, Indonesia. Int Med J Malaysia. 2019;18(2):29-37.

17. Blackford K, Jancey J, Lee AH, James A, Howat P, Waddell T. Effects of a home-based intervention on diet and physical activity behaviours for rural adults with or at risk of metabolic syndrome: A randomised controlled trial. Int J Behav Nutr Phys Act. 2016;13:1-10. https://doi.org/10.1186/s12966-016-0337-2 PMid:26830197

18. Silva MN, Vieira PN, Coutinho SR, Minderico CS, Matos MG, Sardinha LB, et al. Using self-determination theory to promote physical activity and weight control: A randomized controlled trial in women. J Behav Med. 2010;33(2):110-22. https://doi. org/10.1007/s10865-009-9239-y

PMid:20012179

19. Markland D, Ryan RM, Tobin VJ, Rollnick S. Motivational interviewing and self-determination theory. J Soc Clin Psychol. 2005;24:811-31. https://doi.org/10.1521/jscp.2005.24.6.811

20. Patrick H, Williams GC. Self-determination theory: Its application to health behavior and complementarity with motivational interviewing. Int J Behav Nutr Phys Act. 2012;9:1-12. https://doi. org/10.1186/1479-5868-9-18

21. Ministry of Health. Peraturan Menteri Kesehatan Republik Indonesia Nomor 41 tentang Pedoman Gizi Seimbang. Indonesia: Ministry of Health; 2014.

22. Leblanc V, Bégin C, Hudon AM, Royer MM, Corneau L, Dodin S, et al. Effects of a nutritional intervention program based on the self-determination theory and promoting the mediterranean diet. Health Psychol Open. 2016;3(1):1-11. https://doi. org/10.1177/2055102915622094

PMid:28070382

23. Pollard C, Miller M, Woodman RJ, Meng R, Binns C. Changes in knowledge, beliefs, and behaviors related to fruit and vegetable consumption among Western Australian adults from 1995 to 2004. Am J Public Health. 2009;99(1):355-61. https://doi. org/10.2105/ajph.2007.131367

PMid:19059859

24. Wang H, Song Z, Ba Y, Zhu L, Wen Y. Nutritional and eating education improves knowledge and practice of patients with Type 2 diabetes concerning dietary intake and blood glucose control in an outlying city of China. Public Health Nutr. 2013;17(10):23518. https://doi.org/10.1017/s1368980013002735

PMid:24124930

25. Hakli G, Asil E, Uçar A, Özdogan Y, Yilmaz MV, Özçelik AÖ, et al. Nutritional knowledge and behavior of adults: Their relations with sociodemographic factors. Pak J Nutr. 2016;15:532-9. https://doi.org/10.3923/pjn.2016.532.539

26. Mäntyselkä P, Kautiainen H, Miettola J. Beliefs and attitudes towards lifestyle change and risks in primary care a communitybased study. BMC Public Health. 2019;19:1-9. https://doi. org/10.1186/s12889-019-7377-x

27. Ahadi Z, Heshmat R, Sanaei M, Shafiee G, Ghaderpanahi M, Homami MR, et al. Knowledge, attitude and practice of urban 
and rural households towards principles of nutrition in Iran: Results of NUTRIKAP survey. J Diabetes Metab Disord. 2014;13(1):100. https://doi.org/10.1186/s40200-014-0100-7 PMid:25551099

28. Parmenter K, Waller J, Wardle J. Demographic variation in nutrition knowledge in England. Health Educ Res. 2000;15(2):163-74.

PMid: 10751375
29. Downs SM, Farmer A, Quintanilha M, Berry TR, Mager DR, Willows ND, et al. From paper to practice: Barriers to adopting nutrition guidelines in schools. J Nutr Educ Behav. 2012;44(2):114-22. https://doi.org/10.1016/j.jneb.2011.04.005 PMid:22119449

30. Stran KA, Knol LL. Determinants of food label use differ by sex. J Acad Nutr Diet. 2013;113(5):673-9.

PMid:23402696 